\title{
IDENTIFICATION OF POTENTIAL ZONES FOR KIMBERLITE EXPLORATION- AN EARTH OBSERVATION APPROACH
}

\author{
Arindam Guha ${ }^{1}$, Komal Rani ${ }^{2}$, Chandra Bhusan Varma ${ }^{2}$, Nikhil Kr. Sarwate ${ }^{2}$, Nilay Sharma ${ }^{2}$, Abhijeet Mukherjee ${ }^{2}, K_{\text {. Vinod Kumar }}{ }^{1}$, \\ Sanjit $\mathrm{Kr} \mathrm{Pal}^{3}$, Amit Kr. Saw ${ }^{2}$, Sarvesh Kr. Jha ${ }^{3}$ \\ ${ }^{1}$ Geosciences Group, National Remote Sensing Centre, Indian Space Research Organisation, India - arindamisro@gmail.com \\ ${ }^{2}$ NMDC Ltd., Khanij Bhavan, Masab Tank, Hyderabad - 500028 \\ ${ }^{3}$ Department of Geophysics, Indian Institute of Technology (ISM) Dhanbad
}

\section{Commission V, SS: Natural Resources Management}

KEY WORDS: Alteration, ASTER, EIGEN6C4, Geomorphic anomaly, Kimberlite, Logical Operator, Lithology, Lineament

\begin{abstract}
:
In the present study, we have prepared the thematic evidence layers for identifying the potential zones of kimberlite emplacement in parts of Chhatarpur district, Madhya Pradesh. These thematic layers or evidence layers are geological structure, alteration zones, lineament density, surface alteration and geomorphic anomaly and these layers are prepared from the remote sensing data. As orientation of the geological structures (i.e fault system) and their density have the major role in the emplacement of kimberlite; both of these evidence layers are integrated using "AND" Boolean Logical Operator. On the other hand, two evidential layers regarded as the proxy to indicate the "surface expressions on kimberlite (i.e. alteration zones and geomorphic anomaly) are combined using "OR" operator as either of these two surface expression is indicative of kimberlite. Consequently, conjugate evidence layers on the surface expressions of kimberlite are integrated with the causative evidence layers of kimberlite emplacement using "AND" operator to identify the potential zones of diamond occurrences. Potential zones of kimberlite are overlaid on the residual gravity anomaly map derived from space-based gravity model of European Improved Gravity of Earth by New Technique (EIGEN6C4) to relate potential zones of kimberlite with the similar structural alignment (delineated in the residual gravity map) of known occurrence of kimberlite. We also have carried out indicator mineral survey around these potential zones and some of the kimberlite specific indicator minerals are identified in the stream sediments within these potential zones.
\end{abstract}

\section{INTRODUCTION}

Remote Sensing techniques have been used as a tool for exploration and prospecting of kimberlite throughout the world (Wang et al., 1987; Almeida-Filho and Castelo Branco, 1992; Tessema et al., 2012). In this regard, utilisation of remote sensing data was focused to identify the geological controls on kimberlite emplacement (Ramdass et al., 2006; Tessema et al., 2012). Remote sensing data from different sensors are useful to detect direct and indirect evidences suitable for the occurrences of the kimberlite. Direct detection is possible if the fresh kimberlite exposures are available on the surface and these exposures are delineable using the spatial and spectral resolutions of the remotely placed sensors operated either at the space-borne or airborne platforms (Kruse et al., 2003; Guha et al., 2013). Possible scope of direct detection of kimberlite is less as kimberlites are easily weathered and always covered with the thick weathered residuum (Guha et al., 2013). In this scenario, kimberlites can be targeted based on finding some indirect evidences which have known correlation with the kimberlites. These are the presence of specific geomorphic anomalies, specific set up of geological structures (intersection zones of some structure) and alteration residues constituted with the Magnesium rich clay and carbonates (Guha et al., 2013 and Guha et al., 2015). Regional geological structures associated with the extensional tectonic regime are regarded as the suitable conduits for the emplacement of kimberlite or kimberlitic clan of rocks. In this regard, remote sensing data would be suitable for delineating geological structures, their mutual association and possible extensions in the spatial domain due the synoptic coverage of the terrain in the remote sensing images.

Mapping of the structures and their spatial distribution is the key for the diamond exploration. Further, remote sensing data collected from the satellite/aerial platforms also help in understanding the relative variation in the intensity of deformation based on the identification of different zones of contrasting structural fabric or lineament density. This is also important for diamond exploration as density variations in distribution of lineament also contribute in the emplacement of kimberlite. In addition to map the suitable geological structures, satellite data also have their role in delineating subtle geomorphic anomalies based on the identification of circular depression, geomorphic indicators like sudden circular bend of river, moisture patches etc. Spectral anomaly detected by spectral channels of spaceborne sensors would be of utility for delineating surface residue or weathered zones of kimberlite. Many kimberlites are associated Magnesium rich clay and calcretes and these minerals have diagnostic spectral 
signature in their reflectance spectra (Podvysotskiy, 1985; Schumacher, 2012). Prospect maps are prepared by combining the above mentioned causative and resultant evidences of kimberlite emplacement.

Space based gravity data model are processed to derive Bouguer gravity and residual gravity anomaly map to identify the regional, penetrative structures associated with these prospective zones. The association of prospective zones with specific set of structures would provide indirect validations if some of these structures have already emplaced kimberlites in the same geological province. Proposed method of conjugate use of earth observation data along with the space based gravity models to suggest the prospective zones of Kimberlite emplacement are very few in the literature. Further, field work is carried out to find "indicator minerals" in the stream sediments within the prospective zones to further validate these prospective zones. In that context, present study important as it brings out the possible locales of kimberlite in one of the promising Kimberlite occurring belt in India.

\section{GEOLOGY}

The present study area is situated at the northern part of Madhya Pradesh; one of the central state of India. The study area is elongated east-west (from the longitude $79^{0} 25^{\prime}$ to $\left.80^{\circ} 10^{\prime \prime}\right)$. The north south extent of the study area is covered within the latitude extend from $24^{0} 20$ to $24^{0} 44$

Present study area is occupied with the Vindhyan Group of rocks of Proterozoic age. Main rock units of the study area is sandstone, shale. Dolomites are also reported at the central portion of the study area. Coarse grained granites and Metabasalt are reported at the northern fringe of the study area. Many of the adjoining kimberlites; which have been discovered recently are reported within the sandstone. Some of the large lineaments (length greater than $10 \mathrm{~km}$ ) and trending in variable directions are also reported on the study area (Fig.2)

\section{MATERIALS AND METHODS}

\section{a. MATERIALS}

We have used advanced moderate resolution satellite data of Resourcesat-02 for mapping the geological structures, their density. Further, satellite images of Indian Remote Sensing Satellite (IRS) LISS-IV sensor Advanced space borne thermal emission and reflection e Radiometer (ASTER) sensor of EO-1 satellite are used to delineate Magnesium rich alteration zone or weathered residue. The ASTER data product used in this study is level 1B data (registered at sensor radiance data).Detail

Specification of VNIR-SWIR bands of ASTER data are given in the table 1 (Abrams, 2000). In addition to the above datasets, space based gravity model data are used to identify the deeper and penetrative structures with the wider regional expansion. EIGEN-6C4 (European Improved Gravity model of the Earth by New techniques (EIGEN)) is the latest released version of static global combined gravity field model. In EIGEN-6C4 model, different satellite-derived gravity (LAGEOS, GRACE and GOCE data ) data and land surface data sets have been integrated by a band-limited combination of normal equations (to max degree 370) based on spherical harmonic coefficient (Pal et al., 2016 a; Pal et al., 2016b; Förste et al., 2014). In this study, we have used EIGEN6C4 data for deriving Bouguer and residual gravity anomaly map to identify the deeper structures.

\section{b. METHODS}

We have processed IRS-LISS-IV data for preparing the database on the geological themes important for diamond exploration. In this regard structural map, lineament density maps, geomorphic anomaly and alteration anomaly maps are prepared. In addition to above, we also have prepared the base layers (road, settlements, and major drainages). Base layer maps are essential to identify the location of the prospective zones for detailed exploration. Brief outline of the approaches followed for the preparation of different evidence layers are given below.

Derivation of lineament map: We have processed the LISSIV image to derive few image enhanced products of Resourcesat-2 satellite for mapping lineaments and their density. Higher spatial resolution of the LISS-IV data provides the scope to delineate lineament effectively. We have derived lineament map based on conjugate analysis of FCC image composites of Resourcesat-2-LISS-IV sensor and reference geological map of GSI (GSI Unpublished). Lineaments are mapped on the image based on the identification of tonal alignment, identification of the geomorphic element aligned along the specified direction using the spatial geometry of drainage pattern (e.g. drainage alignments, drainage intersection), alignment of scarp, visible displacements of rock units on image etc. In order to map lineament, edge enhancement (3x3 high pass filtered) image of near infrared, red and green spectral bands was used.

Lineament density map: We also have prepared lineament density map to identify the zones with variable structural fabric. In the zones of higher lineament density, lineaments were criss-crossing each other and created network of natural lines with higher lineament density (i.e. number of lineaments in unit area). For creating lineament density, grid size is fixed as $1 \mathrm{~km}$ and the lineament density map is resampled to 30 meter.

Geomorphic anomalies: Certain geomorphic anomalies are used as a proxy for the kimberlites. These geomorphic anomalies are clearly visible on image and they are recorded as point (point is kept on the centre of the identified feature). These geomorphic anomalies are circular anomalies: abnormal circular feature indicating some concealed natural element, circular moisture rich zone and circular drainage pattern. For integration, geomorphic anomaly vector layer was created using the radius of 2 kilometer and we used this vector as one of the evidence layer for identifying the prospective zones.

Alteration zones: We identified alteration zones based on derivation of relative band depth image from the ASTER short wave infrared (SWIR) bands. In this case, three ASTER SWIR bands (band 7, band 8 and band 9) were used to delineate alteration zones for delineating magnesium rich residue or serpentinised residue. We prepared the evidence layer on alteration zones by demarcating those high value pixels in the 
ratio image occurring in vicinity to the larger lineaments (with length greater than $5 \mathrm{~km}$ ) or the high lineament density zones. Alteration pixels identified beyond the zone of influence of structure were regarded as the false positives or false alarm for kimberlite altered product. These pixels are not used in the integration for identification prospective zones of kimberlite.

Derivation of diamond potential zones: We delineated potential zones of diamond occurrences based on identification of some suitable areas having the converging influence of large lineament, high lineament density, presence of alteration zones and geomorphic anomalies. All the themes mentioned above, are integrated using "Boolean logical operator". For identification of the potential zones of kimberlite emplacement, buffer polygons were prepared around the large lineaments having strike length five kilometer or more. High Lineament density and lineament buffer zones of large lineaments were combined using the "AND" operator to derive combined zone of causative factors for kimberlite emplacement. A buffer polygon with $2 \mathrm{~km}$ radius around centre of geomorphic anomaly was used to integrate them with the other themes. On the other hand, we combined buffer zones of geomorphic anomaly and alteration zones using the "OR" operator for deriving combined zone of surface signatures of pipe. Finally, we integrated "combined causative evidences" and "combined surface signatures" using "AND" operator to derive the potential zones of diamond emplacement. Potential zones are categorised with two classes. These are "highly potential" and "moderately potential". In "highly potential" zone; two causative evidences converge with the "combined evidences of surface signatures". In moderately potential zone, two causative evidences converge without the presence of combined evidence of surface signatures of kimberlite.

Validation: We have processed the EIGEN6C4 gravity model data for deriving gravity anomaly map to identify the penetrative structures; which might have allowed the emplacement of the already discovered kimberlites and the spatial proximity of similar structures with the identified potential zones are also examined. In this regard residual anomaly map has been prepared. At first, Bouguer anomaly is derived after applying the correction for mass, distance, topography between the observation point and mean sea level (Telford et al., 1990; Chapin 1996). We have also implemented latitude correction to remove the effect of earth shape (Telford et al., 1990; Chapin 1996). Residual Bouguer anomaly (near Surface anomaly) map has been derived using the Gaussian high pass filter on Bouguer anomaly data in the Geosoft software platform (Wessel 1998).

We have carried out field survey to collect stream sediments from the first and second order channels within the prospective zones. We systematically prepared samples before we identified the indicator minerals using binocular microscope. For sample preparation, samples were subjected to sieving, jigging, density separation and magnetic separation process sequentially to isolate the heavy mineral residue. Each mineral phase was consequently identified.

\section{RESULT AND DISCUSSION}

Present study area is selected for prospectivity analysis because kimberlite pipes are discovered adjacent to the block (Fig.1). We observed that the some of the discovered kimberlites are either exposed along the ENE-WSW, NW-SE trending lineaments. We also found alternation zones, geomorphic anomalies demarcated from the satellite data are in vicinity to these large lineaments.

Lineament and lineament density are regarded as the main causative factors for kimberlite emplacement (Fig. 3.a and b). High resolution satellite image with reasonable swath was suitable to delineate the lineament and lineament density. Other two evidences are alteration zone and geomorphic anomaly; which are the surface impression of concealed pipe (Fig. 3.c and d).

Geomorphic anomalies were either some circular features or some structural intersection (Fig.4). We delineated the high value pixels indicating alterations provided these alterations are vicinity to the $\mathrm{E}-\mathrm{W}$ and $\mathrm{N}-\mathrm{S}$ trending lineaments or occurring at the intersection of these lineaments (Fig.3.d). These penetrative structures are found to be associated with the already discovered Kimberlite pipes (Fig.2). Prospective zones were the areas where favourable controlling factors were operated and these factors were associated with the surface signatures at selected places (Fig.5). It was necessary to conceptually validate the prospective zones to further assess the utility of these zones for discovering kimberlites.

We attempted to use space based gravity model to propose a conceptual validation by identifying penetrative structures. Residual gravity anomaly map derived from satellite based model is capable to delineate these larger regional structures due to distance from which the data were acquired; which invariably enhance the deeper and the larger structures compared to the corresponding ground geophysical data. We found that the potential zones of kimberlites are in vicinity with some of these structures (ENE-WSW and NW-SE trending) as it was the case for the discovered pipes (Fig.6). This conceptually validates the suggested prospective zones. We have carried out detailed stream sediment analysis to collect sample for delineating mineralogical and geochemical proxies of kimberlite(Fig.7).As the first hand results of stream sediment analysis, we identified few indicator minerals from the stream sediments within the identified prospective zones (Fig.7.a,b.). We also could identify the presence of calcretes within the prospective zone. Calcrete is regarded as one of the prospective tool for exploring concealed kimberlites( Roy, 2009).This also provides the first level validation of these prospective zones. Detail geochemical character of these indicator minerals are to be studied along with detailed geophysical survey (e.g. very low frequency (VLF) electromagnetic) to confirm the presence of kimberlites within these prospective zones.

Nevertheless, the study presents the simple approach on the utilisation of earth observation data for kimberlite exploration to provide the guide for detailed exploration. The approach can be utilised to any promising kimberlite province in the world.

\section{CONCLUSIONS}

Following are the conclusions derived from this study. 
1. Integration of causative and resultant factors of kimberlite occurrence is important for identifying the suitable zones for kimberlite emplacement. All the evidence layers are delineable in satellite data

2. Spatial relation of prospective zone with the mega lineament suggested that the prospective zones are in accordance with the structural alignment of discovered pipes. In this case, prospective zones are in vicinity to ENE-WSW and NW-SE trending lineaments.

3. Residual gravity anomaly map suggests the penetrative nature of the large lineaments; which are associated with the potential zones for kimberlite. This suggests that the potential of these lineaments as the conduit for the emplacement of kimberlite. These sets of lineament also have contributed in emplacing some discovered pipe in vicinity to the study area. Presence of promising indicator minerals is also identified within this zone.

4. Presence of similar set of structures as found with the discovered pipe and the initial results of indicator mineral survey suggest the prospective zones are to be studied using the anomaly maps derived from detailed geochemical and ground geophysical datasets to unearth some concealed pipes.

\section{REFERENCES}

6. Drewes, H., Kuglitsch, F., Adám, J., Rózsa, S., 2016. The geodesist's handbook 2016. Journal of Geodesy, 90(10), pp 907-1205.

7. Förste, C., Bruinsma, S., Abrikosov, O., Flechtner, F., Marty, J. C., Lemoine, J. M.,Dahle, C., Neumayer, H.,Barthelmes, F., Konig, R., Biancale, R., 2014. EIGEN-6C4-The latest combined global gravity field model including GOCE data up to degree and order 1949 of GFZ Potsdam and GRGS Toulouse. In EGU General Assembly Conference Abstracts (Vol. 16).

8. Guha, A., Rao, D. A., Ravi, S., Kumar, K. V., Rao, E. D., 2012. Analysis of the potential of kimberlite rock spectra as spectral end member using samples from Narayanpet Kimberlite Field, Andhra Pradesh. Current Science, 103(9), pp 1096-1104.

9. Guha, A., Kumar, K. V., Ravi, S., Rao, E. D., 2015. Reflectance Spectroscopy of Kimberlites - in parts of Dharwar Craton, India. Arabian Journal of Geosciences (Springer), 8(11), pp 9373-9388

10. Guha, A., Rao, D., Ananth, Ravi, S., Kumar, K. Vinod., Rao, E. N. Dhananjaya., 2013. Issues and Limitations of Broad Band Remote Sensing of Kimberlite-A Case Example from
1. Abrams, M., 2002. The Advanced Spaceborne Thermal Emission and Reflection Radiometer (ASTER): Data products for the high spatial resolution imager on NASA's Terra platform. International Journal of Remote Sensing, 21 (5), pp 847-859.

2. Averill, S.A., 2001. The application of heavy indicator mineralogy in mineral exploration with emphasis on base metal indicators in glaciated metamorphic and plutonic terrains. Geological Society, London, Special Publications, 185(1), pp 69-81.

3. Almeida-Filho, R., Castelo Branco, R. M. G., 1992. Location of kimberlites using Landsat Thematic Mapper images and aerial photographs: the Redondao diatreme, Brazil. International Journal of Remote Sensing, 13(8), pp 1449-1457.

4. Chapin, D.A., 1996. The theory of the Bouguer gravity anomaly: A tutorial. The Leading Edge, 15(5), pp 361-363.

5. Clark, R.N., King, T.V., Klejwa, M., Swayze, G.A. and Vergo, N., 1990. High spectral resolution reflectance spectroscopy of minerals. Journal of Geophysical Research: Solid Earth, 95(B8), pp 12653-12680.

Kimberlites of Dharwar Craton, India. International Journal of Geosciences, 4, pp 371379

11. Kruse, F.A., Boardman, J.W., Huntington, J.F., 2003. Comparison of airborne Hyperspectral data and EO-1 Hyperion for mineral mapping. IEEE Transactions on Geoscience and Remote Sensing, 41, pp 1388-1400.

12. Ramdass, G., Himabindu, D., Veeraiah, B., 2006. Morphostructral Prognostication of Kimberlites in Parts of Eastern Dharwar Craton: Inferences from Remote Sensing and Gravity Signatures. Journal of the Indian Society of Remote Sensing, 34(2), 111-121.

13. Roy, A., 2009. Calcrete to kimberlite: A prospector's hunt for "kimberlite traits" in calcretes. Journal of the Geological Society of India, 73(3), p.320.

14. Spiegelhalter, D. J., 1986. Uncertainty in expert systems, in Gale, W. A., ed., Artificial Intelligence and Statistics: Addison-Wesley Reading, Massachusetts, p. 17-55.

15. Tessema, A., Nefale, N., Sebake, D., 2012. The use of high-resolution airborne magnetic, ASTER and Landsat 7 ETM+ images for identification of kimberlite pipes in the north western Free State Province, South Africa. 
International Journal of Remote Sensing, 33:14, pp 4356-4373.

16. Telford, W. M., Geldart, L. P., Sheriff, R. E., 1990. Applied geophysics (Vol. 1). Cambridge university press.

17. Pal, S. K., Majumdar, T. J., Pathak, V. K., Narayan, S., Kumar, U., Goswami, O. P., 2016. Utilization of high-resolution EGM2008 gravity data for geological exploration over the Singhbhum-Orissa Craton, India. Geocarto International, 31(7), 783-802.

18. Pal, S. K., Narayan, S., Majumdar, T. J., Kumar, U., 2016. Structural mapping over the $85^{\circ}$ E Ridge and surroundings using EIGEN6C4 high-resolution global combined gravity field model: an integrated approach. Marine Geophysical Research, 37(3), 159-184.

19. Podvysotskiy, V.T., 1985. Serpentine-carbonate mineralization in kimberlites. International Geology Review, 27(7), pp 810-823.

20. Schumacher, J. C., 2012. Serpentine in kimberlite: an indicator of water rich primary or externally-derived fluid? In European Mineralogical Conference, 2012, vol. 1, p. 593.

21. Wessel, P., 1998. An empirical method for optimal robust regional-residual separation of geophysical data. Mathematical Geology, 30(4), pp 391-408.

22. Wang, P. Q., 1987. Predicting the location of kimberlite from a probability analysis of linear structure on remote sensing data, International Journal of Remote Sensing, Vol. 8:3, pp 417426.

\begin{tabular}{|c|c|c|c|}
\hline Sensor & Spatial & $\mu$ Bands & $\begin{array}{c}\text { Wavelength/other specific } \\
\text { parameters }\end{array}$ \\
\hline $\begin{array}{l}\text { Advanced Spaceborne } \\
\text { Thermal Emission Reflection } \\
\text { Radiometer (ASTER) }\end{array}$ & $30 \mathrm{~m}$ & $\begin{array}{l}\text { SWIR ( Six Short wave infrared } \\
\text { bands are used) } \\
\text { VNIR bands are used for }\end{array}$ & $\begin{array}{c}0.52-0.60 \mu \mathrm{m} \\
0.63-0.69 \mu \mathrm{m} \\
0.78-0.86 \mu \mathrm{m} \\
1.6-1.7 \mu \mathrm{m} \\
2.145-2.185 \mu \mathrm{m} \\
2.185-2.225 \mu \mathrm{m} \\
2.235-2.285 \mu \mathrm{m} \\
2.285-2.360 \mu \mathrm{m} \\
2.2360-2.430 \mu \mathrm{m}\end{array}$ \\
\hline 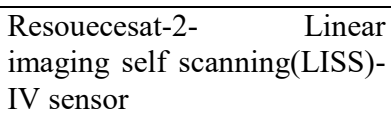 & $\begin{array}{c}5.6 \mathrm{~m} \text { with Swath } 70 \\
\mathrm{~km}\end{array}$ & Three bands & $\begin{array}{l}0.52-0.59 \mu \mathrm{m} \\
0.62-0.68 \mu \mathrm{m} \\
0.77-0.86 \mu \mathrm{m}\end{array}$ \\
\hline Geological map, GSI & $(1: 50,000$ scale $)$ & $\begin{array}{l}----- \\
\end{array}$ & ----- \\
\hline EIGEN6C4 Gravity model & $5 \mathrm{~km}$ & ----- & \\
\hline
\end{tabular}

Table 1: Specification of the datasets used for the study 


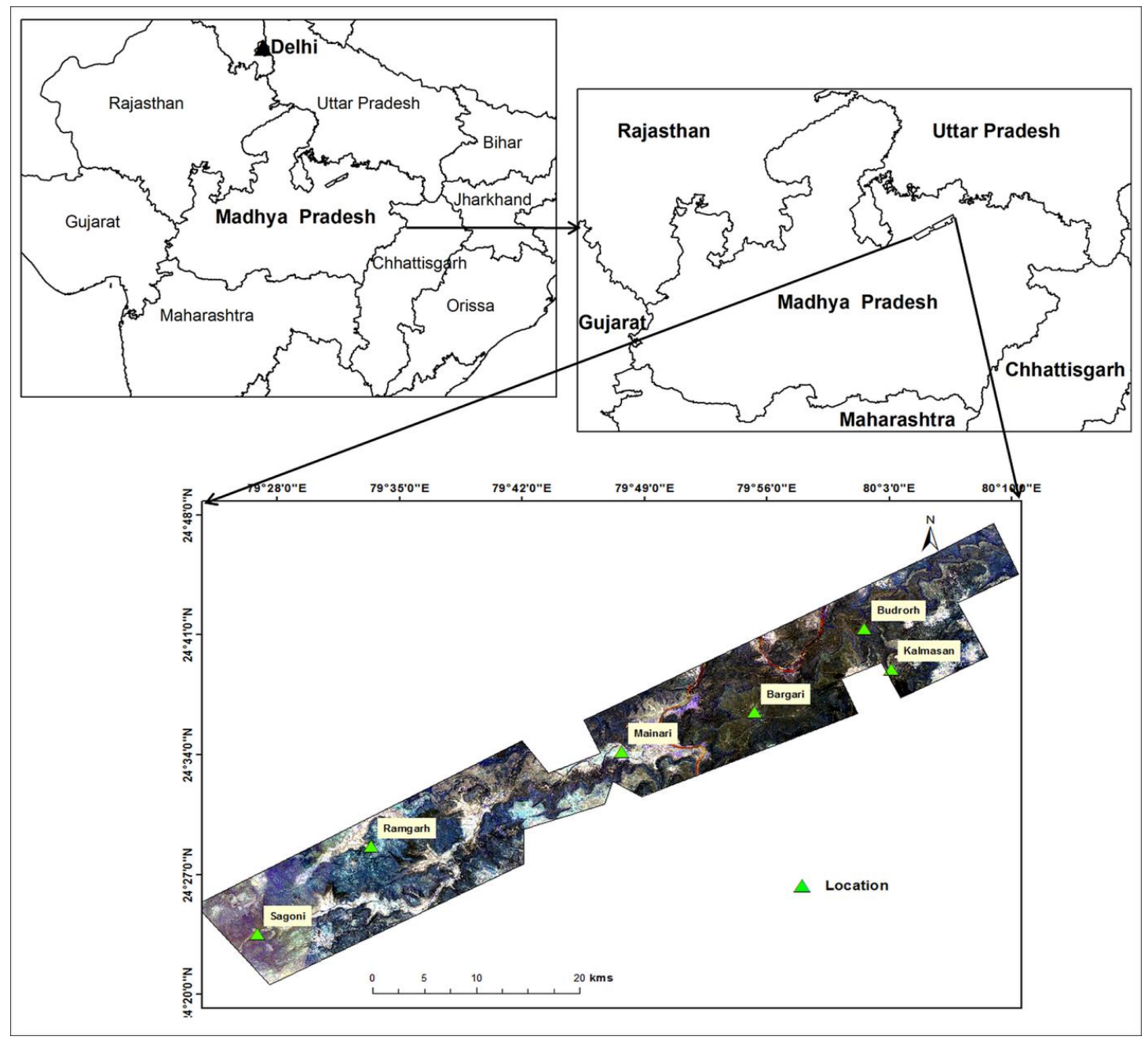

Figure 1. Study area map showing political outline of the state Madhya Pradesh in the which the present study site is located. LISS-IV colour composite image with Red-Green-Blue display is shown( In the FCC image, Red=band 4, Green= band 3 and Blue= band 2). 


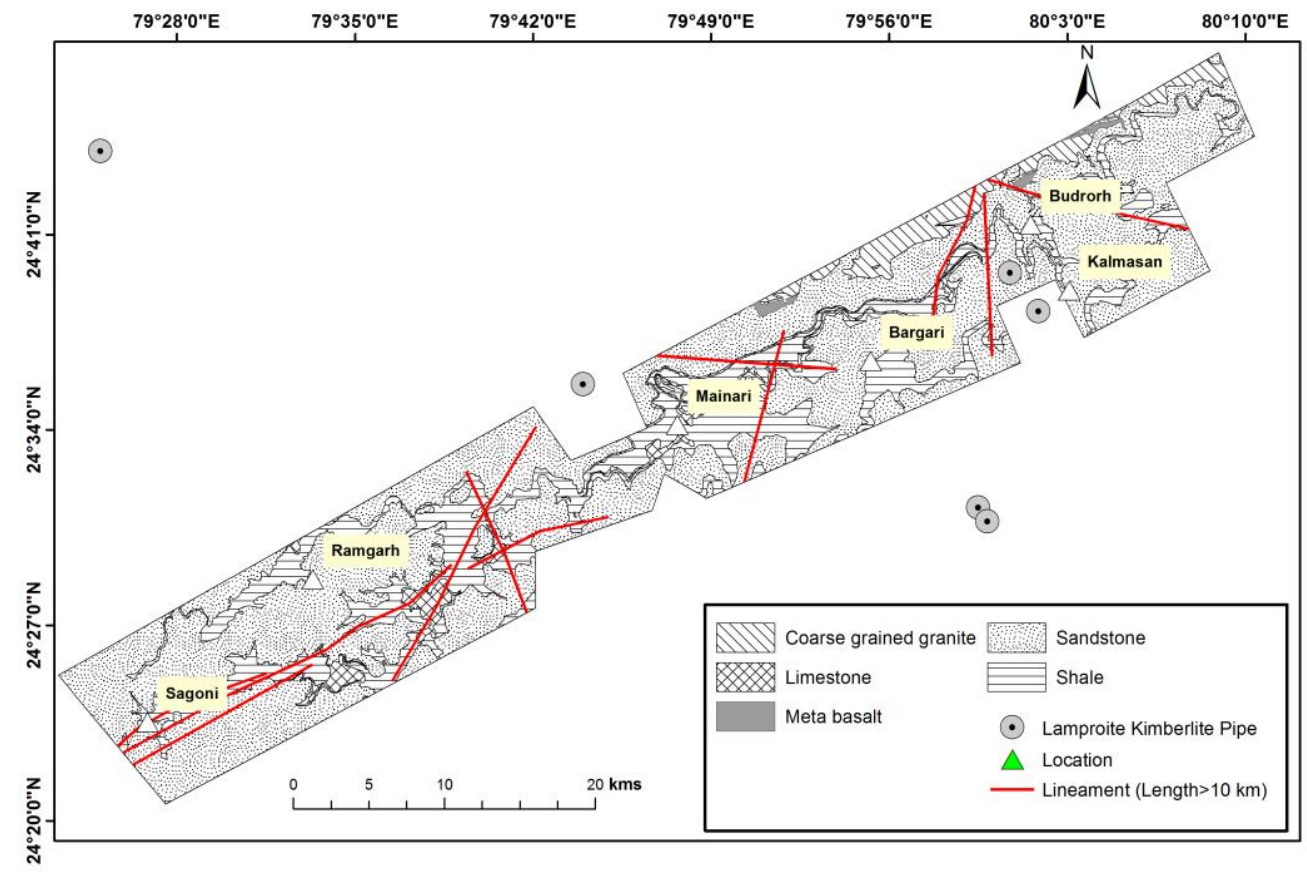

Figure 2. Lithological map of the study area with few large lineament and few discovered kimberlite/lamproite pipe( Source: GSI map, Unpublished)

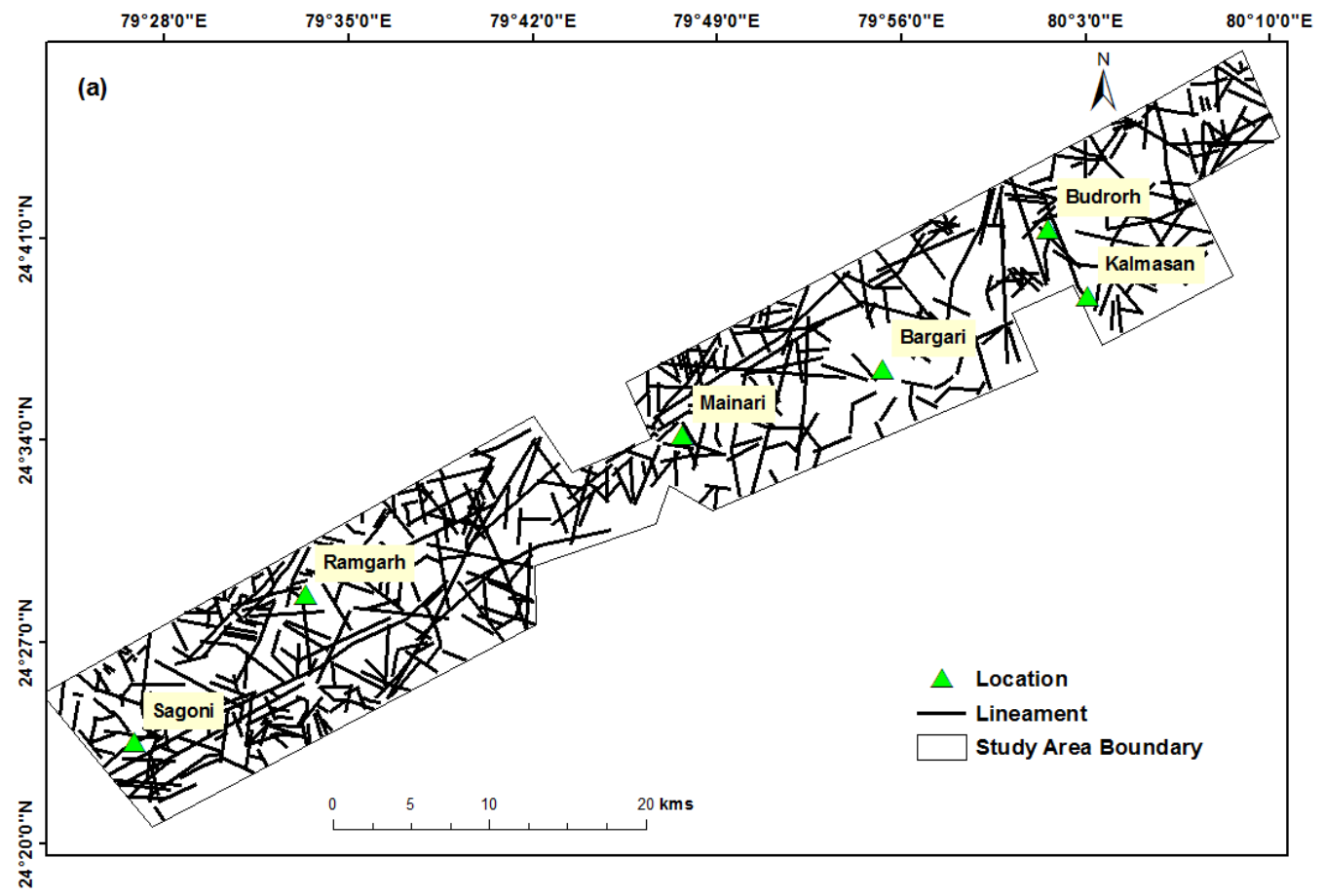



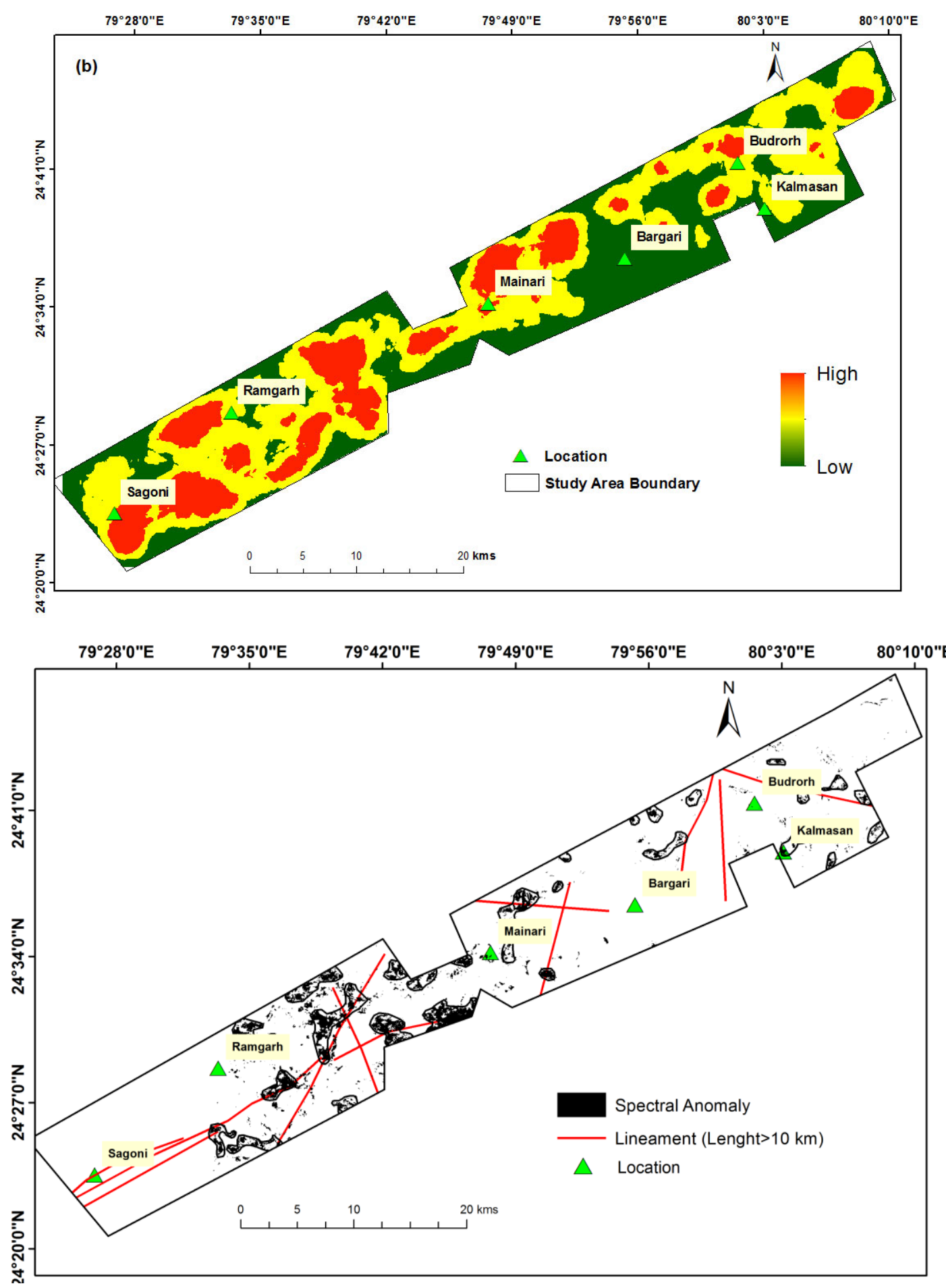


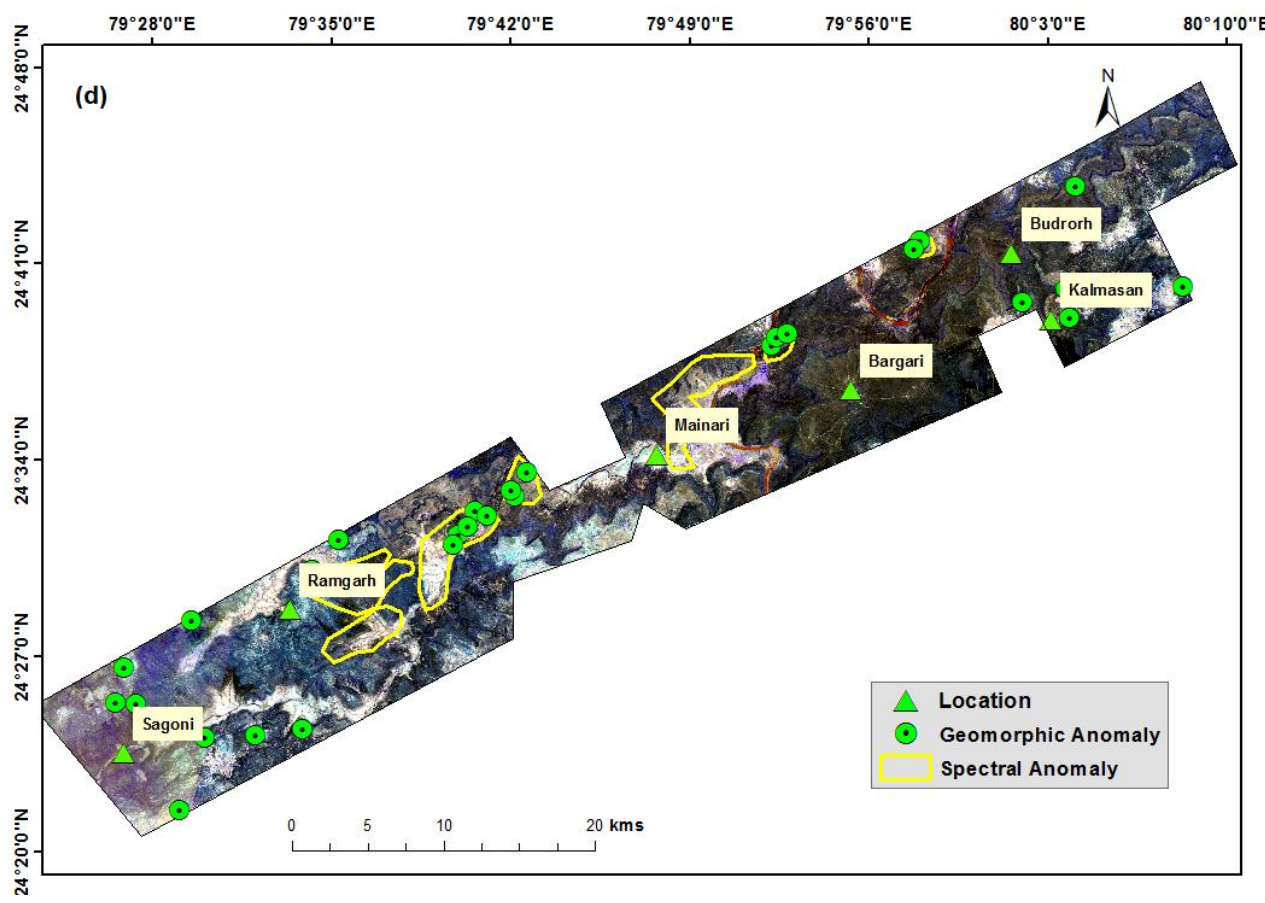

Figure 3. Geological evidences used for deriving the potential zones .a. Lineament( only lineament greater than $5 \mathrm{~km}$ length were used to derive lineament buffer map. b. Lineament density. $\mathrm{C}$ alteration map (ASTER data were available for $80 \%$ of the study area)d.Points of geomorphic anomaly are draped above the

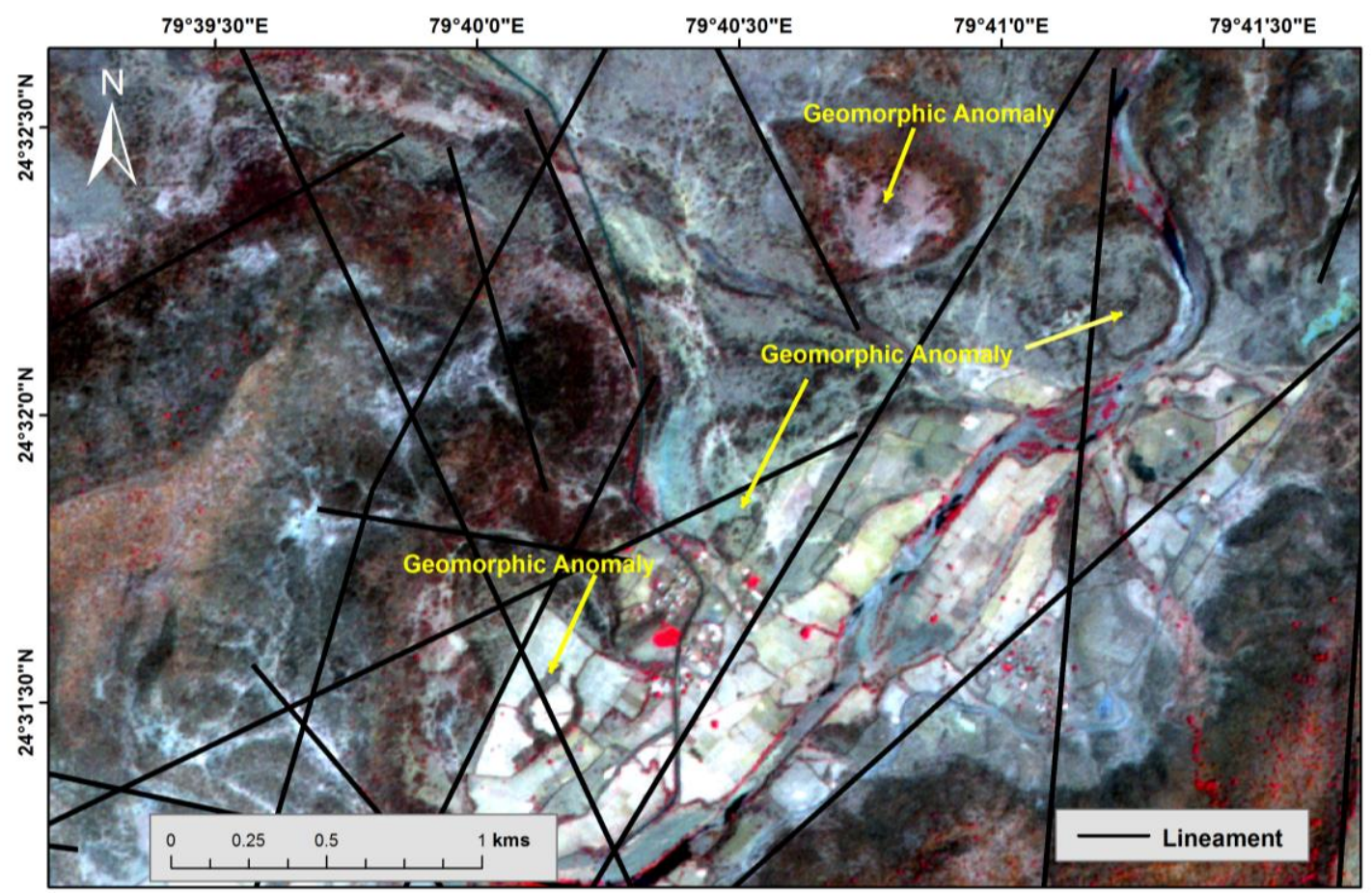

Figure 4: Identification of geomorphic anomaly on satellite imagery 


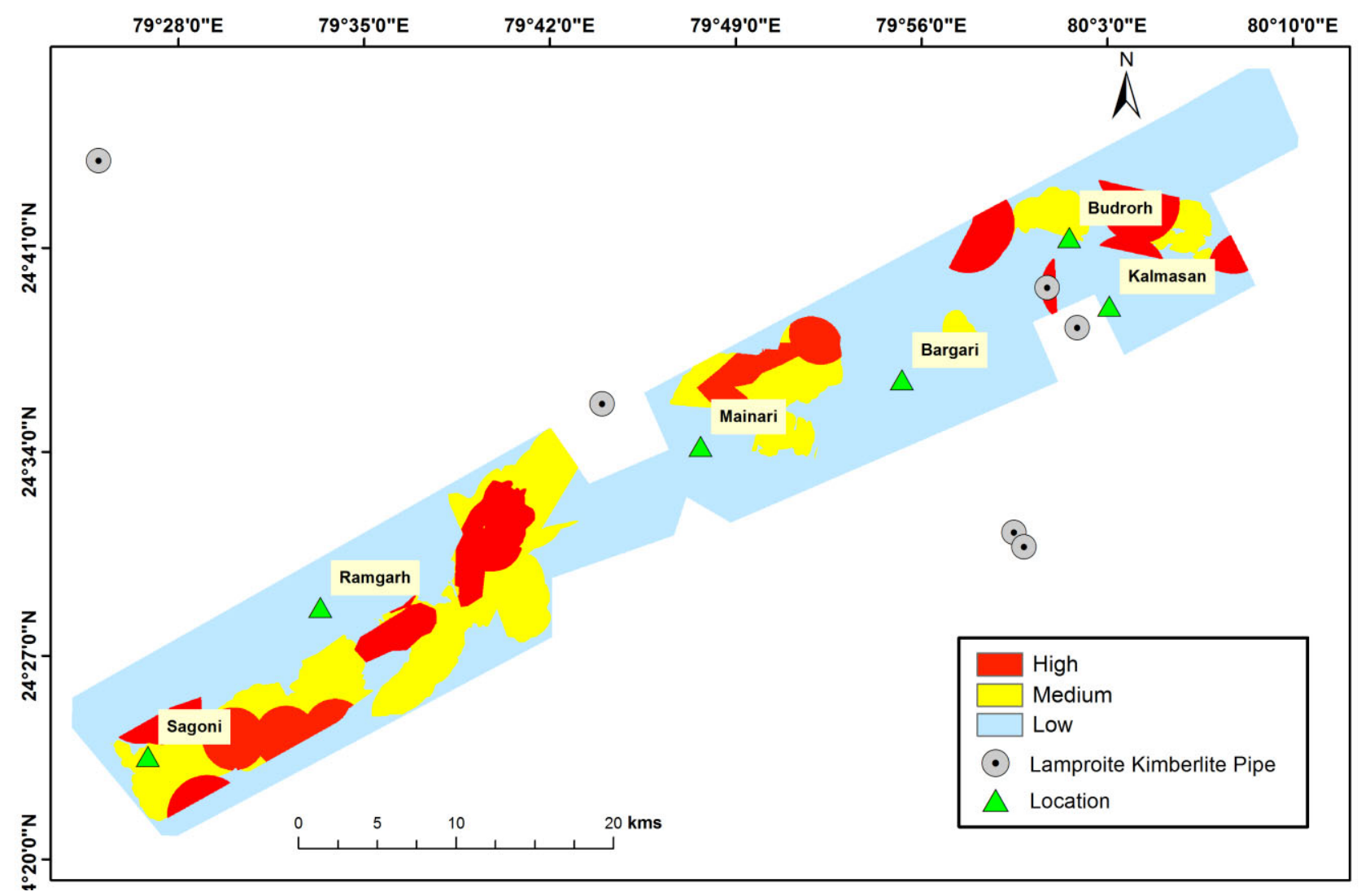

Figure 5: Prospective zones for kimberlite exploration 


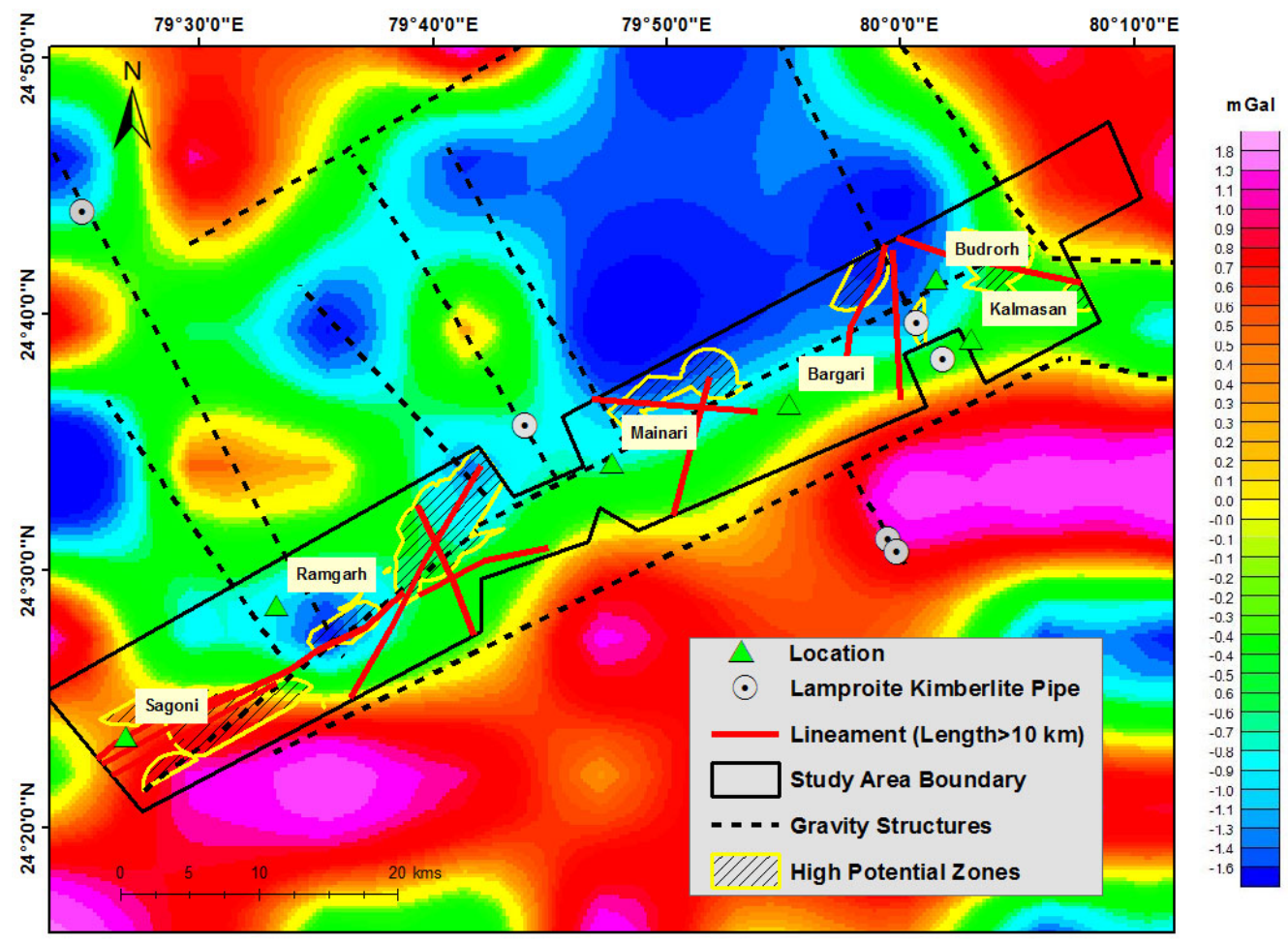

Figure 6. Residual gravity anomaly map showing spatial proximity of prospective zones and lineaments; which have been associated with the discovered pipe. Combined zones of high and moderately potential zones are shown as the out line of prospective zone.
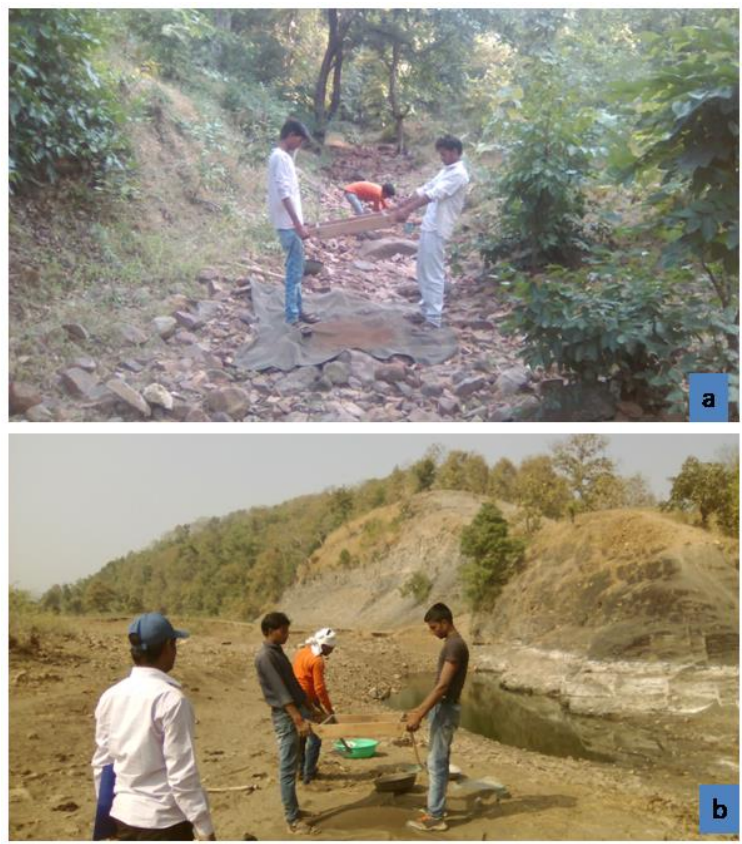

Figure 7: a. Samples collection at the stream occurring within the prospective zones. b. Sample preparation for identifying the indicator minerals 


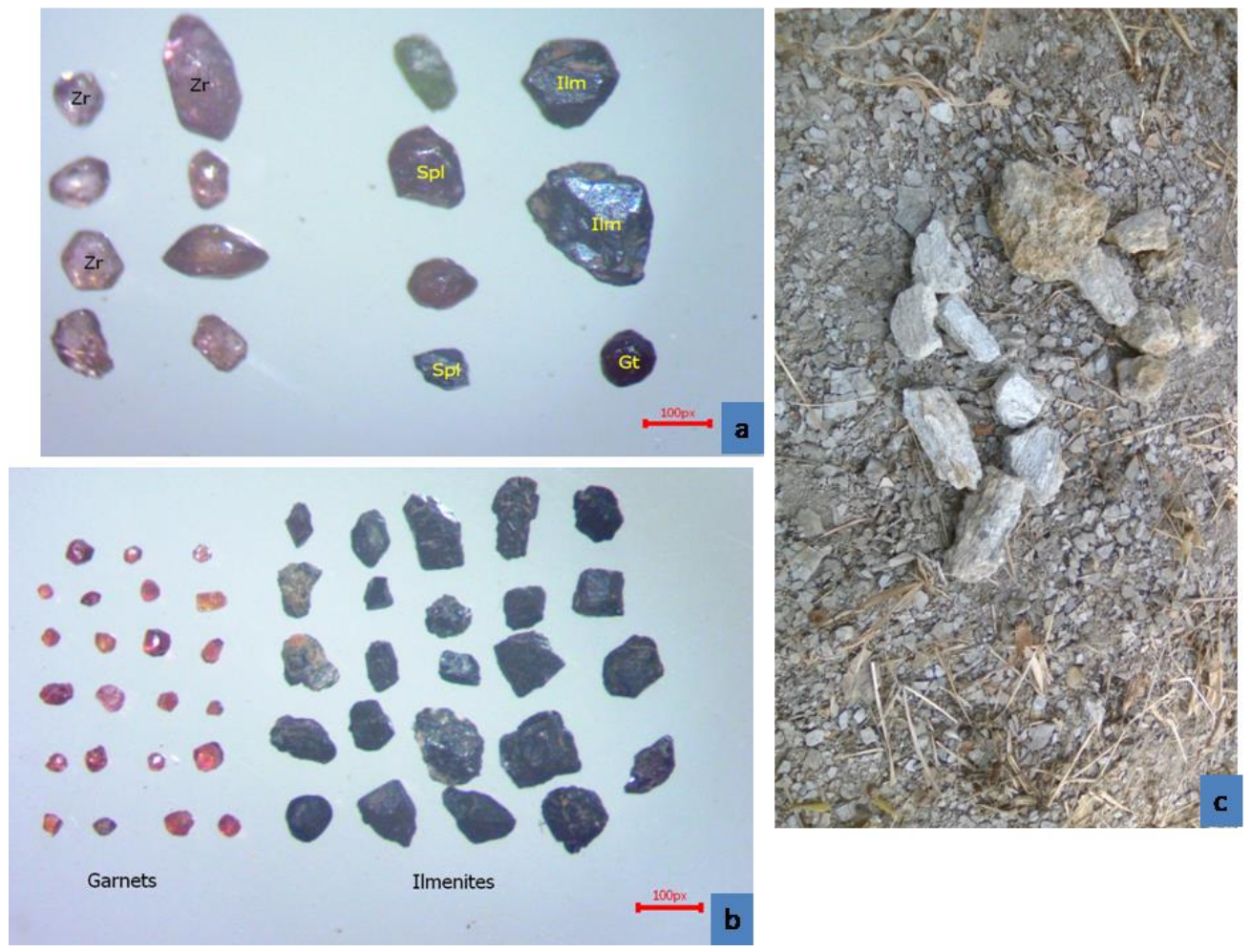

Figure 8: a Zircon, spinel and illmenite identified in the stream sediments within the prospective zones. b.Garnet and illmenite identified in the stream sediments within the prospective zones.c. Calcrete identified in the prospective zones. 